\title{
Reply to K. Altundag
}

\author{
E. A. Underwood ${ }^{1} \cdot$ M. C. Tierney ${ }^{1}$
}

Received: 29 January 2018 / Accepted: 31 January 2018 / Published online: 6 February 2018

(c) Springer Science+Business Media, LLC, part of Springer Nature 2018

We thank Dr. Altundag for his comments on our recent meta-analysis [1]. In his Letter, Dr. Altundag rightly points out that chemotherapy exposure in breast cancer control groups could affect cognitive functioning in these patients. We recognized this and did, in fact, take chemotherapy exposure into account in our meta-analysis.

There is a considerable body of evidence indicating that chemotherapy may exert its own adverse effects on various aspects of cognitive functioning [2]. It is for this reason that we recorded rates of chemotherapy exposure in ET patient and breast cancer control groups for all studies included in our meta-analysis, and presented these data in Table 1.

Most of the studies included in our meta-analysis were performed using chemotherapy-naïve participants. As can be seen in Table 1, however, there were two studies in which a proportion of the breast cancer control group had been treated with chemotherapy. In each of these studies, a similar proportion of the ET group had also received chemotherapy treatment. Information regarding the schedules or duration of chemotherapy was not described in these studies.

Meta-regression analyses, in which rates of chemotherapy exposure in both ET patients and breast control groups were included as covariates, revealed no moderating effect of chemotherapy exposure on ET patient versus control comparisons for any cognitive domain. Thus, while chemotherapy exposure is undoubtedly an important consideration in studies examining the cognitive effects of ET, it did not appear to have any appreciable influence on the results of our meta-analysis. As we note in our discussion, this may be due to the small number of studies that included any participants exposed to chemotherapy in the first place.

Funding Information No funding was received for this Letter to the Editor.

\section{Compliance with ethical standards}

Conflict of Interest The authors declare that they have no conflict of interest.

Ethical approval For this type of article (Letter to the Editor), no ethical approval or formal consent is required.

\section{References}

1. Underwood EA, Rochon PA, Moineddin R, Lee PE, Wu W, Pritchard KI, Tierney MC (2017) Cognitive sequelae of endocrine therapy in women treated for breast cancer: a meta-analysis. Breast Cancer Res Treat. https://doi.org/10.1007/s1054 9-017-4627-4

2. Vitali M, Ripamonti CI, Roila F, Proto C, Signorelli D, Imbimbo M, Corrao G, Brissa A, Rosaria G, de Braud F, Garassino MC, Lo Russo G Cognitive impairment and chemotherapy: a brief overview. Crit. Rev. Oncol/Hematol 118:7-14. https://doi. org/10.1016/j.critrevonc.2017.08.001
This rebuttal letter refers to the letter to the editor available at doi: https://doi.org/10.1007/s10549-018-4672-7.

\footnotetext{
M. C. Tierney

mary.tierney@sunnybrook.ca

1 Primary Care Research Unit, Department of Family and Community Medicine, Sunnybrook Health Sciences Centre, 2075 Bayview Avenue, Suite E349, Toronto, ON M4N 3M5, Canada
} 